\title{
Shock Index in COVID Era
}

\author{
Souvik Dey ${ }^{1} \quad$ Rohan Magoon $^{1} \quad$ Jasvinder Kaur Kohli ${ }^{1}$ Ramesh Chand Kashav ${ }^{1} \quad$ ItiShri $^{1}$ Ashish Walian ${ }^{1}$ \\ ${ }^{1}$ Department of Cardiac Anaesthesia, Atal Bihari Vajpayee Institute of \\ Medical Sciences (ABVIMS) and Dr. Ram Manohar Lohia Hospital, \\ New Delhi, India \\ J Card Crit Care 2021;5:268-272. \\ Address for correspondence Ramesh Chand Kashav, Department of \\ Cardiac Anaesthesia, Atal Bihari Vajpayee Institute of Medical \\ Sciences (ABVIMS) and Dr. Ram Manohar Lohia Hospital, Baba Kharak \\ Singh Marg, New Delhi 110001, India (e-mail: drkashav@yahoo.co.in).
}

\author{
Abstract \\ Keywords \\ - coronavirus disease \\ 2019 \\ - risk stratification \\ - shock index \\ - health care burden \\ - level of patient care
}

The health care burden and risks to health care workers imposed by novel coronavirus disease 2019 (COVID-19) mandated the need for a simple, noninvasive, objective, and parsimonious risk stratification system predicting the level of care, need for definitive airway, and titration of the ongoing patient care. Shock index ( $\mathrm{SI}=$ heart rate/systolic blood pressure) has been evaluated in emergency triage, sepsis, and trauma settings including different age group of patients. The ever accumulating girth of evidences demonstrated a superior predictive value of SI over other hemodynamic parameters. Inclusion of respiratory and/or neurological parameters and adjustment of the cutoffs appropriate to patient age increase the predictability in the trauma and sepsis scenario. Being reproducible, dynamic, and simple, SI can be a valuable patient risk stratification tool in this ongoing era of COVID-19 pandemic.

\section{Introduction}

Shock, a clinical state of impaired oxygen delivery or utilization, is a major cause of mortality, morbidity, and increased resource utilization in the critically ill patient cohort. ${ }^{1}$ Timesensitive intervention and treatment as emphasized by the early researches mandate the need of an early identification strategy. ${ }^{2,3}$ In this context, an exhaustive list of clinical, hemodynamic, and laboratory parameters ( - Table $\mathbf{1}$ ) have been evaluated in various surgical and nonsurgical patient populations. However, a mere correction of the these parameters doesn't necessarily improve outcome in shock patients. ${ }^{4}$ Moreover, lack of specificity, invasive nature of the laboratory parameters, and need of additional monitoring equipments and expertise (such as $\mathrm{ScvO}_{2}$ [central venous oxygen saturation], cardiac output, echocardiography, etc.) construct the ground to formulate other novel risk stratification parameters.
In conjunction to the aforementioned fact, a derived hemodynamic parameter, shock index $(\mathrm{SI}=$ heart rate $[\mathrm{HR}]$ /systolic blood pressure [SBP]) emerged as a simple, noninvasive, bedside, and objective parameter to predict the outcome and risk stratification in shock patients.

\section{Types of SI}

Originally SI was formulated to include both vascular and myocardial component (as reflected by SBP and HR, respectively) and a value more than the normal range (0.5-0.9) predicted poor tissue perfusion as evidenced by a positive correlation with serum lactate and mixed venous oxygen saturation. ${ }^{5}$ Subsequently, several modifications have been made to address the aforementioned issue as enlisted in -Table 2. Additionally, respiratory rate and $\mathrm{SpO}_{2}$
DOI https://doi.org/ 10.1055/s-0041-1739499. ISSN 2457-0206. (c) 2022. Official Publication of The Simulation Society (TSS), accredited by International Society of Cardiovascular Ultrasound (ISCU). All rights reserved.

This is an open access article published by Thieme under the terms of the Creative Commons Attribution-NonDerivative-NonCommercial-License, permitting copying and reproduction so long as the original work is given appropriate credit. Contents may not be used for commercial purposes, or adapted, remixed, transformed or built upon. (https://creativecommons.org/ licenses/by-nc-nd/4.0/)

Thieme Medical and Scientific Publishers Pvt. Ltd., A-12, 2nd Floor, Sector 2, Noida-201301 UP, India 
Table 1 Commonly employed methods for evaluation of shock

\begin{tabular}{|c|c|c|}
\hline Clinical parameters & Hemodynamic parameters & Laboratory parameters \\
\hline $\begin{array}{l}\text { - Mental status } \\
\text { - Temperature of the extremities } \\
\text { - Urine output } \\
\text { - Capillary refill time (in seconds) }\end{array}$ & $\begin{array}{l}\text { - HR } \\
\text { - Blood pressure (invasive/noninvasive) } \\
\text { - PA catheter-based monitoring } \\
\text { - Echocardiography-based monitoring }\end{array}$ & $\begin{array}{l}\text { - ABG analysis } \\
\text { - Serum lactate } \\
\text { - Hematocrit } \\
\text { - Mixed/central venous oxygen saturation }\end{array}$ \\
\hline
\end{tabular}

Abbreviations: $\mathrm{ABG}$, arterial blood gas; $\mathrm{HR}$, heart rate; PA catheter, pulmonary artery catheter.

Table 2 Different types of shock indices

\begin{tabular}{|l|l|}
\hline Types of indices & Formula to calculate indices \\
\hline SI & HR/SAP \\
\hline MSI & HR/MAP \\
\hline DSI & HR/DAP \\
\hline rSI & SAP/HR \\
\hline Age SI & Age $\times(\mathrm{HR} / \mathrm{SAP})$ \\
\hline SIPA & HR/SAP \\
\hline RASI & (HR/SAP $) \times$ RR/10 \\
\hline SS & (HR/SAP $) / S p O_{2}$ \\
\hline rSIG & GCS $\times(S A P / H R)$ \\
\hline SIPF & $\begin{array}{l}\text { HR/SAP }>0.7(1 \text { point })+\mathrm{PaO}_{2} / \mathrm{FiO}_{2} \\
<250(1 \text { point })=\text { total } 0-2 \text { points }^{2}\end{array}$ \\
\hline
\end{tabular}

Abbreviations: AgeSI, age-adjusted shock index; DAP, diastolic arterial pressure; DSI, diastolic shock index; GCS, Glasgow Coma Scale; HR, heart rate; MAP, mean arterial pressure; MSI, modified shock index; RASI, respiratory adjusted shock index; rSI, reversed shock index; rSIG, reversed shock index multiplied with GCS; SAP, systolic arterial pressure; SI, shock index; SIPA, shock index pediatric age-adjusted; SIPF, shock index and hypoxemia; SS, shock index to $\mathrm{SpO}_{2}$ ratio.

[peripheral blood oxygen saturation] have been introduced along with SI to incorporate the respiratory component (-Table 2).

\section{Where Can it Help (in CovID-19)?}

Despite the continuous endeavor and ongoing researches, little is known about the novel coronavirus disease 2019 (COVID-19) and subsequent management of the patients requiring intensive care unit (ICU) admission. According to few studies, about 5 to $10 \%$ of the patients infected with severe acute respiratory syndrome coronavirus 2 (SARSCoV-2) require ICU admission. ${ }^{6}$ Shock (up to $67 \%$ of patients admitted in the ICU) has been implicated as the primary cause of death in 7\% of COVID-19 cases and as a contributing factor in an additional 33\%. ${ }^{7}$ All the four types of shock (hypovolemic, cardiogenic, distributive, and obstructive) have been observed in COVID-19 patients owing to the peculiar pathophysiology of the disease-hypovolemia occurring due to the associated fever, diarrhea, and fluid restrictive treatment protocol; systemic inflammation with circulating cytokine storm giving the etiology of septic/distributive shock; a direct injury to the myocardium due to myocarditis and pulmonary hypertension (caused by positive pressure ventilation, chronic hypoxia, pulmonary fibrosis) leading to right ventricular dilatation, all can attribute to the myocardial dysfunction leading to cardiogenic shock; and, finally, sudden pulmonary thromboembolism (owing to the inherent hypercoagulable disease pathology) and tension pneumothorax form the etiology of obstructive shock. ${ }^{8}$ Therefore, a close monitoring and early detection of the shock pathology are the cornerstone for a better outcome. On the other hand, a breach in the safety precautions adapted by the health care workers (HCW) in the process of patient care imposes a unique challenge in the ongoing COVID-19 pandemic. To address the this issue, the World Health Organization (https://www.who.int/publications-detail/clinical-management-of-severe-acuterespiratory-infection-when-novel-coronavirus-(ncov)-infectionis-suspected) and the National Institutes of Health (https://covid19treatmentguidelines.nih.gov/critical-care/hemodynamics/) released recommendations for the hemodynamic management of COVID-19 patients, ensuring minimum number of exposures for the HCWs without compromising patient safety. However, indication for endotracheal intubation in COVID-19 patients is controversial, albeit it carries the greatest risk of exposure (by aerosol generation). Previous researches recommend a lower threshold for endotracheal intubation (and mechanical ventilation) despite low arterial oxygen saturation. ${ }^{8}$ Compensation by the cardiovascular system may have a pivotal role as described by Tobin and colleagues. ${ }^{9}$ SI and its modifications might play a crucial role by indicating the compensatory cardiovascular reserve. On the other hand, being a noninvasive, continuous, and objective parameter, SI can be a valuable tool in the triage area (to determine the level of care) as well as in the inpatient management in titrating the treatment protocol without exhausting resources of the already overburdened health care system.

\section{Encouraging Literatures}

\section{Diverse Patient Populations}

Till date, various scoring system and indices have been evaluated in COVID-19 patients for prognostication and risk stratification, with variable success. In this context, quick sequential organ failure assessment score (qSOFA), combining respiratory rate, neurological status, and hemodynamics; CURB 65; NEWS (National Early Warning Score); and 4C mortality scores have been validated with improved predictive efficacy. ${ }^{10}$ The available literature demonstrated the equivalent efficacy of SI with qSOFA in trauma triage scenario. ${ }^{11}$ Another study depicted the positive correlation between serum lactate and diastolic SI and 
Table 3 Shock indices evaluated in different patient cohort

\begin{tabular}{|l|l|l|l|}
\hline Patient cohort & $\begin{array}{l}\text { Variants of SI } \\
\text { studied }\end{array}$ & Other parameters compared & Conclusion \\
\hline Trauma & SI, MSI, AgeSI & $\begin{array}{l}\text { ABC Score, DBP, SBP, HR, } \\
\text { RTS, REMS }\end{array}$ & $\begin{array}{l}\text { SI correlates with increased need for MTP, performs } \\
\text { equally with ABC score } \\
\text { MSI is a better predictor than SI and other hemodynamic } \\
\text { parameters }\end{array}$ \\
\hline Triage & SI, MSI, AgeSI & SBP & $\begin{array}{l}\text { SI is a better predictor of inpatient mortality but not } \\
\text { admission to ICU }\end{array}$ \\
\hline Sepsis & SI & CVP, SIRS & High NPV with normal SI for lactate $<4.0$ mmol/L \\
\hline Obstetric & SI & HR, SBP & SI consistently higher in ruptured ectopic pregnancy \\
\hline Pediatric & SIPA & $\begin{array}{l}\text { SI, SBP, DBP, age-adjusted } \\
\text { hypotension }\end{array}$ & SIPA has higher sensitivity and specificity \\
\hline Geriatric & SI & Age SI, MSI, HR, SBP & Higher specificity \\
\hline
\end{tabular}

Abbreviations: AgeSI, age-adjusted shock index; CVP, central venous pressure; DBP, diastolic blood pressure; HR, heart rate; MSI, modified shock index; SI, shock index; SIPA, shock index pediatric age-adjusted.

better prognostic efficacy in septic shock patient cohort recruited from ANDROMEDA-SHOCK trial. ${ }^{12}$ Similarly, respiratory adjusted shock index (RASI) and shock index to $\mathrm{SpO}_{2}$ ratio (SS) have been validated in acute respiratory distress syndrome (ARDS) and community-acquired pneumonia patients to predict the need for mechanical ventilation and hospitalization. ${ }^{13,14}$ Jiang and colleagues have successfully applied RASI in sepsis for identifying occult shock and subsequent triage of the patients for the level of care required. ${ }^{13}$ Adjusting the cutoff appropriate for age, Ray and colleagues ${ }^{15}$ highlighted a better predictive efficacy of on admission SI pediatric age-adjusted (SIPA) over the conventional hemodynamic parameters (SBP, HR) and positive correlation with arterial lactate level. Utility of SI in different patient subgroups is enlisted in - Table 3.

\section{Ambiguity in Cutoff}

An increased SI value universally indicates hypoperfusion. However, there is no universal consensus regarding the cutoff value for SI in adult patients. Previous researches demonstrated multiple cutoff values as documented in - Table 4. $^{16-21}$

\section{Limitations of SI}

First, SI value doesn't change over a wide range of cardiovascular compensatory phase (increase in heart rate to compensate hypotension), particularly in the younger age group. Second, the mode of blood pressure recording (invasive vs. noninvasive) is not universal in the existing literature. Accordingly, the variations in systolic, diastolic, and mean blood pressure between noninvasive and invasive method would create ambiguity in calculating the SI value, specifically in the shock state.

\section{Conclusion}

SI, a noninvasive, simple, dynamic, objective, and parsimonious index, can appropriately predict the outcome in COVID-19 patients and upgrade the patient care in a timely
Table 4 Different cutoffs for shock indices

\begin{tabular}{|l|l|l|}
\hline $\begin{array}{l}\text { Patient } \\
\text { cohort }\end{array}$ & $\begin{array}{l}\text { Cutoff } \\
\text { for SI }\end{array}$ & Study types and outcome \\
\hline Triage & $\begin{array}{l}0.5-0.7 \\
>0.7 \\
>1\end{array}$ & $\begin{array}{l}\text { Retrospective cohort of } 58,336 \\
\text { patients with a highest likelihood } \\
\text { ratio to admission and mortality } \\
\text { with SI }>1.2^{16}\end{array}$ \\
\hline Trauma & $>0.7$ & $\begin{array}{l}\text { Retrospective cohort; better } \\
\text { predictor of preceding bleeding and } \\
\text { initiation of MTP } 17,18\end{array}$ \\
& $>0.9$ & \\
& $>1.3$ & $\begin{array}{l}\text { Both prospective (280 patients) and } \\
\text { retrospective (56 patients) studies, } \\
\text { better ability to predict ruptured } \\
\text { ectopic pregnancy }\end{array}$ \\
\hline Obstetrics & $>0.7$ \\
& $>0.85$ & $\begin{array}{l}\text { Retrospective cohort of 2,524 } \\
\text { patients, SI as a predictor of } \\
\text { vasopressor use, in patient } \\
\text { mortality } 21\end{array}$ \\
\hline Sepsis & $>0.7$ \\
& $>1$ &
\end{tabular}

Abbreviations: MTP, massive transfusion protocol; SI, shock index.

manner. ${ }^{22}$ As it is aptly said, to be forewarned is to be forearmed and half the victory.

Conflict of Interest

None declared.

\section{References}

1 Vincent J-L, De Backer D. Circulatory shock. N Engl J Med 2013;369 (18):1726-1734

2 Rivers E, Nguyen B, Havstad S, et al; Early Goal-Directed Therapy Collaborative Group. Early goal-directed therapy in the treatment of severe sepsis and septic shock. N Engl J Med 2001;345(19): $1368-1377$

3 Osborn TM, Nguyen HB, Rivers EP. Emergency medicine and the surviving sepsis campaign: an international approach to 
managing severe sepsis and septic shock. Ann Emerg Med 2005; 46(03):228-231

4 Magoon R. Physiological status monitoring with shock indices: context and precision equally matter!. Am J Emerg Med 2020; 24:31067-31068

5 Singh A, Ali S, Agarwal A, Srivastava RN. Correlation of shock index and modified shock index with the outcome of adult trauma patients: a prospective study of 9860 patients. N Am J Med Sci 2014;6(09):450-452

6 Alhazzani W, Møller MH, Arabi YM, et al. Surviving sepsis campaign: guidelines on the management of critically ill adults with coronavirus disease 2019 (COVID-19). Crit Care Med 2020; 48(06):e440-e469

7 Ruan Q, Yang K, Wang W, Jiang L, Song J. Clinical predictors of mortality due to COVID-19 based on an analysis of data of 150 patients from Wuhan, China. Intensive Care Med 2020;46(05): 846-848

8 Fox S, Vashisht R, Siuba M, Dugar S. Evaluation and management of shock in patients with COVID-19. Cleve Clin J Med 2020

9 Tobin MJ, Jubran A, Laghi F. Hypoxaemia does not necessitate tracheal intubation in COVID-19 patients. Comment on $\mathrm{Br} \mathrm{J}$ Anaesth 2021; 126: 44-7. Br J Anaesth 2021;126(02):e75-e76

10 Su Y, Tu GW, Ju MJ, et al. Comparison of CRB-65 and quick sepsisrelated organ failure assessment for predicting the need for intensive respiratory or vasopressor support in patients with COVID-19. J Infect 2020;81(04):647-679

11 Harada M, Takahashi T, Haga Y, Nishikawa T. Comparative study on quick sequential organ failure assessment, systemic inflammatory response syndrome and the shock index in prehospital emergency patients: single-site retrospective study. Acute Med Surg 2019;6(02):131-137

12 Ospina-Tascón GA, Teboul JL, Hernandez G, et al. Diastolic shock index and clinical outcomes in patients with septic shock. Ann Intensive Care 2020;10(01):41
13 Jiang L, Caputo ND, Chang BP. Respiratory adjusted shock index for identifying occult shock and level of Care in Sepsis Patients. Am J Emerg Med 2019;37(03):506-509

14 Qi J, Ding L, Bao L, Chen D. The ratio of shock index to pulse oxygen saturation predicting mortality of emergency trauma patients. PLoS One 2020;15(07):e0236094

15 Ray S, Cvetkovic M, Brierley J, et al. Shock index values and trends in pediatric sepsis: predictors or therapeutic targets? A retrospective observational study. Shock 2016;46(03):279-286

16 Balhara KS, Hsieh YH, Hamade B, Circh R, Kelen GD, Bayram JD. Clinical metrics in emergency medicine: the shock index and the probability of hospital admission and inpatient mortality. Emerg Med J 2017;34(02):89-94

17 Vandromme MJ, Griffin RL, Kerby JD, McGwin G Jr, Rue LW III, Weinberg JA. Identifying risk for massive transfusion in the relatively normotensive patient: utility of the prehospital shock index. J Trauma 2011;70(02):384-388, discussion 388-390

18 DeMuro JP, Simmons S, Jax J, Gianelli SM. Application of the Shock Index to the prediction of need for hemostasis intervention. Am J Emerg Med 2013;31(08):1260-1263

19 Schroll R, Swift D, Tatum D, et al. Accuracy of shock index versus $A B C$ score to predict need for massive transfusion in trauma patients. Injury 2018;49(01):15-19

20 Birkhahn RH, Gaeta TJ, Van Deusen SK, Tloczkowski J. The ability of traditional vital signs and shock index to identify ruptured ectopic pregnancy. Am J ObstetGynecol 2003;189(05): 1293-1296

21 Berger T, Green J, Horeczko T, et al. Shock index and early recognition of sepsis in the emergency department: pilot study. West J Emerg Med 2013;14(02):168-174

22 Doğanay F, Elkonca F, Seyhan AU, Yılmaz E, Batırel A, Ak R. Shock index as a predictor of mortality among the COVID-19 patients. Am J Emerg Med 2020;40:106-109 